\title{
BioControl
}

\section{The invasive stink bug Halyomorpha halys affects the reproductive success and the experience-mediated behavioural responses of the egg parasitoid Trissolcus basalis --Manuscript Draft--}

\begin{tabular}{|c|c|c|}
\hline \multicolumn{3}{|l|}{ Manuscript Number: } \\
\hline Full Title: & \multicolumn{2}{|c|}{$\begin{array}{l}\text { The invasive stink bug Halyomorpha halys affects the reproductive success and the } \\
\text { experience-mediated behavioural responses of the egg parasitoid Trissolcus basalis }\end{array}$} \\
\hline Article Type: & \multicolumn{2}{|l|}{ Original Article } \\
\hline Keywords: & \multicolumn{2}{|c|}{$\begin{array}{l}\text { host-parasitoid interaction; parasitoid foraging behaviour; parasitoid fitness; } \\
\text { evolutionary trap }\end{array}$} \\
\hline Corresponding Author: & \multicolumn{2}{|l|}{$\begin{array}{l}\text { antonino cusumano, PhD } \\
\text { University of Palermo } \\
\text { ITALY }\end{array}$} \\
\hline \multicolumn{3}{|l|}{$\begin{array}{l}\text { Corresponding Author Secondary } \\
\text { Information: }\end{array}$} \\
\hline Corresponding Author's Institution: & \multicolumn{2}{|l|}{ University of Palermo } \\
\hline \multicolumn{3}{|l|}{$\begin{array}{l}\text { Corresponding Author's Secondary } \\
\text { Institution: }\end{array}$} \\
\hline First Author: & \multicolumn{2}{|l|}{ Ezio Peri } \\
\hline \multicolumn{3}{|l|}{ First Author Secondary Information: } \\
\hline \multirow[t]{5}{*}{ Order of Authors: } & \multicolumn{2}{|l|}{ Ezio Peri } \\
\hline & \multicolumn{2}{|l|}{ Maria Cristina Foti } \\
\hline & \multicolumn{2}{|l|}{ Letiza Martorana } \\
\hline & \multicolumn{2}{|l|}{ antonino cusumano, $\mathrm{PhD}$} \\
\hline & \multicolumn{2}{|l|}{ Stefano Colazza } \\
\hline \multicolumn{3}{|c|}{ Order of Authors Secondary Information: } \\
\hline Funding Information: & $\begin{array}{l}\text { H2020 Marie Skłodowska-Curie Actions } \\
\text { (INVASIoN (GA 690952)) }\end{array}$ & Not applicable \\
\hline Abstract: & \multicolumn{2}{|c|}{$\begin{array}{l}\text { Invasive species, because of their lack of co-evolutionary history with recipient } \\
\text { communities, can act as "evolutionary traps" causing disconnects between natural } \\
\text { enemy behavioural responses and the suitability of the invasive species as a prey } \\
\text { resource. Invasion of exotic species in non-native environments may have several } \\
\text { ecological effects, including consequences for the experience-mediated behavioural } \\
\text { responses of indigenous foragers. Experience is usually thought to help resident } \\
\text { species to buffer against negative impacts of new invasive species, including escaping } \\
\text { from evolutionary traps. Here we hypothesized that the impact of foraging experience } \\
\text { depends on whether an indigenous egg parasitoid can correctly assess the resource } \\
\text { suitability of a new invasive species for offspring development. We showed that the } \\
\text { invasive stink bug Halyomorpha halys acts as an evolutionary trap for the indigenous } \\
\text { egg parasitoid Trissolcus basalis leading to unsuccessful development of } \sim 95 \% \text { of the } \\
\text { eggs laid in this host species. In a mixed scenario in which both the associated } \\
\text { resident stink bug Nezara viridula co-occur with the invasive H. halys, we showed } \\
\text { that oviposition experience in the low quality invasive host induces in T. basalis } \\
\text { similar responses to those of the associated host; thus foraging experience does not } \\
\text { lead to avoidance of an evolutionary trap. We discuss parasitoid foraging experience } \\
\text { and reproductive success in the light of the evolutionary trap framework with } \\
\text { implication for biological control. }\end{array}$} \\
\hline Suggested Reviewers: & \multicolumn{2}{|l|}{$\begin{array}{l}\text { Tim Haye } \\
\text { CABI Switzerland } \\
\text { t.haye@cabi.org }\end{array}$} \\
\hline
\end{tabular}


expert in invasive pest species

Luciana Tavella

Universita degli Studi di Torino Dipartimento di Scienze Agrarie Forestali e Alimentari luciana.tavella@unito.it

expert in biological control agents 
Dear editor,

Please, find submitted our manuscript entitled " The invasive stink bug Halyomorpha halys affects the reproductive success and the experience-mediated behavioural responses of the egg parasitoid Trissolcus basalis". In this paper we show that the invasive stink bug Halyomorpha halys acts as an evolutionary trap for Trissolcus basalis, an egg parasitoid closely associated with the stink bug Nezara viridula. In a series of experiments, we provided behavioural evidence showing that experience on cues associated with $H$. halys affects the subsequent foraging behaviour of $T$. basalis. Yet such responses do not lead to the avoidance of the evolutionary trap, and consequently, do not always maximize the reproductive success of the wasp. We are requesting consideration for publication in BioControl.

Best regards

Antonino Cusumano on the behalf of all co-authors

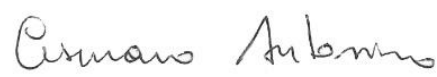




\section{Authors list and affiliation}

Ezio Peri ${ }^{1}$, Foti Maria Cristina ${ }^{1}$, Letizia Martorana ${ }^{1}$, Antonino Cusumano $^{1 *}$, Stefano Colazza $^{1}$

${ }^{1}$ Department of Agricultural, Food and Forest Sciences, University of Palermo Viale delle Scienze 5,

90128 Palermo, Italy

*Corresponding author: antonino.cusumano@unipa.it

author(s) details 
1 To be submitted to: biocontrol

2 The invasive stink bug Halyomorpha halys affects the reproductive

3 success and the experience-mediated behavioural responses of the

$4 \quad$ egg parasitoid Trissolcus basalis

5 


\section{Abstract}

7 Invasive species, because of their lack of co-evolutionary history with recipient communities,

8 can act as "evolutionary traps" causing disconnects between natural enemy behavioural

9 responses and the suitability of the invasive species as a prey resource. Invasion of exotic

10 species in non-native environments may have several ecological effects, including

11 consequences for the experience-mediated behavioural responses of indigenous foragers.

12 Experience is usually thought to help resident species to buffer against negative impacts of

13 new invasive species, including escaping from evolutionary traps. Here we hypothesized that

14 the impact of foraging experience depends on whether an indigenous egg parasitoid can correctly assess the resource suitability of a new invasive species for offspring development.

We showed that the invasive stink bug Halyomorpha halys acts as an evolutionary trap for

17 the indigenous egg parasitoid Trissolcus basalis leading to unsuccessful development of

$18 \sim 95 \%$ of the eggs laid in this host species. In a mixed scenario in which both the associated resident stink bug Nezara viridula co-occur with the invasive $H$. halys, we showed that oviposition experience in the low quality invasive host induces in T. basalis similar responses to those of the associated host; thus foraging experience does not lead to avoidance of an evolutionary trap. We discuss parasitoid foraging experience and reproductive success in the light of the evolutionary trap framework with implication for biological control. 
Accidental introduction of exotic species is a common by-product of globalization. Some of these invading organisms are of serious concern for the stability and functioning of ecological processes in their invaded environment (Gandhi and Herms 2010; Vilá et al. 2011). Exotic species may have several direct and indirect effects on indigenous organisms (Kenis et al 2009). For example, they may represent a new resource for indigenous predators, and several studies have focused on the exploitation of exotic prey by natural enemies (Berkvens et al. 2010; Carlsson et al. 2009; Sloggett 2010). Indirect effects between native and exotic hosts or prey can also occur, as for example when species interactions are mediated by a shared natural enemy (apparent competition sensu Holt 1977) (Kenis et al. 2009; Redman and Scriber 2000; Settle and Wilson 1990).

Exotic host or prey species can also shape the learning capacity of indigenous foragers. Experience gathered while foraging allows animals to adjust their behavioural responses to variable ecological conditions buffering, under some circumstances, against the introduction of invasive species (Robertson and Blumstein 2019). Experience could be especially important for indigenous foragers encountering "evolutionary traps", i.e. new, unsuitable prey or host species present in the environment that possess cues similar to those of native, suitable species (Schlaepfer et al. 2002, 2005). How foraging experience may shape the responses of arthropod natural enemies against evolutionary traps is unclear, but it is usually thought to help resident organisms to escape from evolutionary traps (Robertson and Blumstein 2019).

Among natural enemies, insect parasitoids are excellent model organisms to study experience and learning because of the plasticity of their behavioural responses when foraging for resources whose exploitation is tightly linked to the parasitoid's fitness (Smid and Vet 2016). Parasitoids must find hosts that are scattered throughout complex and 
heterogenous environments (Aartsma et al. 2019; Meiners and Peri 2013). To successfully locate their hosts, parasitoids can exploit a variety of cues among which chemical cues called infochemicals or semiochemicals, play a key role (Colazza et al. 2014; Fatouros et al. 2008; Vinson et al. 1998). Foraging experience allows parasitoids to dynamically adjust their responses to infochemicals based on how reliable they are associated with the hosts, and finetune their foraging strategies accordingly. While there is evidence of invasive host insects acting as evolutionary traps for parasitoids (Abram et al. 2014; Hoogendoorn and Heimpel 2002), experimental evidence on how parasitoid responses change after gathering foraging experience is limited (Bertoldi 2020).

The brown marmorated stink bug Halyomorpha halys, (Stål) (Heteroptera:

Pentatomidae), is a polyphagous stink bug pest of Asian origin that has invaded both North America and Europe causing major economic losses in diverse crops (Leskey and Nielsen 2018; Rice et al. 2014). From an ecological point of view, $H$. halys has the potential to share the same community structures of resident stink bug pests, especially of other highly polyphagous insects such as the green stink bug Nezara viridula (L.) (Heteroptera: Pentatomidae). The egg parasitoid Trissolcus basalis (Wollaston) (Hymenoptera: Scelionidae) is the main natural enemy of $N$. viridula and both organisms likely originated from the Palearctic/Ethiopian regions (Jones 1988; Salerno 2000; Talamas et al. 2017; Todd 1989). This wasp has been used worldwide in classical, augmentative and conservation biological control programs (Foti et al 2019, Corrêa-Ferreira and Moscardi 1996; Todd et al. 1989). To locate its pentatomid hosts, scelionid egg parasitoids display an innate arrestment response to cuticular hydrocarbons associated with walking traces (i.e. footprints) of adult stink bugs (Colazza et al. 2014). The hierarchical value of the footprints depends on host gender: T. basalis wasps explore intensively those associated with female stink bugs, which are more likely associated with host egg presence (Peri et al. 2013). The innate response to 
footprints is affected by experience so that the response decreases in intensity when wasps reencountered patches without hosts (i.e. unrewarded experience), but it can be restored on patches where oviposition occurred (i.e. rewarded experience) (Peri et al. 2006, 2016). The mechanism underlying parasitoids' responsiveness to footprints has been shown to have several characteristics of habituation, a form of non-associative learning (Abram et al. 2017). These characteristics include a decrease of the response intensity following unrewarded experiences in an interval-dependent manner, i.e. wasps display a decline in response which is more rapid and pronounced when footprints are re-encountered without hosts at shorter intervals (Abram et al. 2017).

Because H. halys and N. viridula already co-occur in several geographical regions of the globe, and the degree of overlap is likely to be extended due to the range expanding status of the invasive species, it can be common for the egg parasitoid T. basalis to encounter patches in which egg masses and footprints of both stink bug species are present. Thus $T$. basalis represents an interesting organism to study how experience can shape the responses of resident parasitoids in the presence of invasive species. There is already evidence that $H$. halys may be a potent evolutionary trap for other species of egg parasitoids in invaded areas. For example, in North America, some indigenous egg parasitoid species, such as Telenomus podisi (Ashmed) (Hymenoptera: Scelionidae) and Trissolcus euschisti (Ashmead) (Hymenoptera: Scelionidae), readily oviposit in H. halys eggs, although wasps cannot develop in this invasive stink bug species (Abram et al. 2014; Konopka et al 2018, 2020). On the contrary, other indigenous egg parasitoid species, such as Ooencyrtus telenomicida (Vassiliev) (Hymenoptera: Encyrtidae) and Anastatus bifasciatus (Geoffroy) (Hymenoptera: Eupelmidae) which successfully exploit $H$. halys eggs, may selectively benefit from an additional suitable resource present in the environment, thus increasing their reproductive success (Haye et al. 2015; Roversi et al. 2016). 
101 foraging experience in T. basalis. In details we explored: 1) the reproductive success of the

102 egg parasitoid on the associated and invasive species in order to assess whether $H$. halys can

103 act as an evolutionary trap for T. basalis; 2) the innate response of $T$. basalis to chemical

104 footprints on the invasive stink bug species in order to assess if the egg parasitoid can

105 recognize the chemical cues left by males or females adults; 3) whether a successful

106 oviposition experience by $T$. basalis on $H$. halys eggs affects the subsequent response to

107 chemical footprints of the invasive species at different time intervals. Finally, in a mixed

108 scenario in which both the associated resident stink bug Nezara viridula co-occur with the

109 invasive $H$. halys, we evaluated several possible combinations of rewarded (i.e. oviposition)

110 and/or unrewarded (i.e. footprints) experiences. 
Insect colonies

Stink bug colonies of $N$. viridula and $H$. halys were held in insect cages $(47.5 \times 47.5 \times 47.5$ cm, BugDorm-44545, MegaView Science Co. Ltd, Taichung, Taiwan), in an environmental room $\left(24 \pm 1^{\circ} \mathrm{C}, 70 \pm 5 \% \mathrm{RH}, 16 \mathrm{~h}: 8 \mathrm{~h} \mathrm{~L}: \mathrm{D}\right)$, and fed with a diet of sunflower seeds and seasonal fresh organic vegetables. Food was changed every 2-3 days, and separate cages were used for immatures and adults. Paper towels were placed inside each adult cage as ovipositional substrates. Daily collected egg masses were used to maintain the colonies and to carry on the experiments afterwards described. The colonies of $N$. viridula and H. halys were established from bugs collected around Palermo, Sicily (southern Italy). The colony of $T$. basalis was established from wasps emerging from sentinel and or naturally laid $N$. viridula egg masses on cultivated and un-cultivated fields in the Palermo area. Parasitoids were kept allow for mating.

\section{Experiment 1. Reproductive success of egg parasitoids developing in the invasive stink}

\section{bug species}

The aim of the exposure of $H$. halys egg masses to $T$. basalis was to evaluate the potential suitability of exotic host eggs for the egg parasitoid and whether $H$. halys could act as an evolutionary trap (i.e. whether wasps accept $H$. halys eggs at high levels, but their offspring would not emerge). Fresh $H$. halys egg masses ( $<24 \mathrm{~h}$ old) were offered to three days old $T$. basalis in 16-ml glass tubes for $24 \mathrm{~h}$. As positive controls we exposed fresh egg masses 
137 ( $<24 \mathrm{~h}$ old) of $N$. viridula, the associated host of $T$. basalis, under the same experimental

138 conditions. The host eggs in which parasitoids have successfully oviposited can be identified

139 because T. basalis marks the parasitized host by sweeping its ovipositor on the chorion

140 surface. Such marking behaviour is highly correlated with egg deposition (Cusumano et al.

141 2011; Abram et al. 2014). During the trials high levels of acceptance were observed regardless of the identity of the stink bug eggs (MCF and LM personal observations). The few wasps that rejected the egg masses (i.e. no marking behaviour was observed) within 30 minutes from their release were removed and replaced with new ones.

After $24 \mathrm{~h}$, parasitoids were removed and the exposed egg masses were stored under controlled conditions $\left(24 \pm 1^{\circ} \mathrm{C}, 80 \pm 5 \% \mathrm{RH}, 16 \mathrm{~h}: 8 \mathrm{~h} \mathrm{~L}: \mathrm{D}\right)$ until parasitoid or nymph emergence. Emergence of parasitoids, mortality of stink bug eggs and emergence of nymphs were recorded. For both treatments (H. halys and $N$. viridula), 18 replicates were carried out.

To assess baseline developmental success of both $H$. halys and $N$. viridula, we included additional controls with unexposed egg masses ( $\mathrm{N}=10$ for both stink bug species).

To further compare the fitness of egg parasitoids reared on eggs of $H$. halys or $N$. viridula, the size of the emerging wasp females was estimated by measuring the hind tibia length rather than measuring the weight of the wasps due to their minute size. Measurements were taken carried out.

Experiment 2. Egg parasitoid response to chemical footprints of adult stink bugs: general bioassays procedure

In this experiment we evaluated the responses of $T$. basalis females to the chemical footprints left by stink bugs females. The general procedure consisted of bioassays carried out in open 
arenas made of a sheet of filter paper $(20 \times 20 \cdot \mathrm{cm}$; wasp/arena surface ratio: $0.002 \%)$. In the middle of each arena, a circular area $(6 \cdot \mathrm{cm}$ diameter $)$ was defined and exposed for $30 \cdot \min$ to a single adult of $H$. halys or $N$. viridula, leaving the surrounding area untreated. This was achieved by constraining the bugs under a steel mesh cover $(6 \cdot \mathrm{cm}$ diameter, $1 \cdot \mathrm{cm}$ high, $0.01 \cdot \mathrm{cm}$ mesh) to ensure constant contact of the bug legs with the filter paper and, at the same time, to avoid surface contamination with bug volatiles. Filter papers contaminated by bug's faeces were not used for bioassays. After removing the bug, according with the following experiments, a female wasp was gently released in the middle of the circular area. Experiments started when the wasp displayed the typical arrestment behaviour (i.e. the wasp intensively drummed with the antennae the area contaminated with stink bug footprints) and lasted until it flew away from or walked off the whole arena. Female wasps that did not show the arrestment behaviour, and either flew away or walked off the arena immediately as a consequence of lack of contact of their antennae with the treated area, were excluded from the analysis. Wasp behaviour was monitored with a CCD camera (Sony M370) equipped with a zoom lens and mounted above the centre of the arena and analysed with "Xbug", a video tracking system and motion analysis software (Peri et al 2006). The arrestment responses of the female wasps were quantified over the entire arena (pooling both outside and inside the circular contaminated area) by means of the total arena residence time (s). Experiments were carried out from $09: 00 \cdot \mathrm{h}$ to $12: 00 \cdot \mathrm{h}$ in an isolated room at $25 \pm 1{ }^{\circ} \mathrm{C}$ illuminated by two $18 \cdot \mathrm{cm}$ long fluorescent tubes.

\section{Experiment 2a. Egg parasitoid innate responses to chemical footprints of the invasive}

\section{stink bug species}

The aim of this experiment was to investigate whether naive $T$. basalis females can recognize the chemical footprints left by $H$. halys. If a response was observed, we were also interested to see if wasps display host gender discrimination, i.e. if they spend more time on the traces 
left by female bugs which would normally be of higher hierarchical value, being more likely associated with egg presence (Peri et al. 2006, 2016). Adults of H. halys used to contaminate the circular area of the filter paper arena were either males or females taken from the colony and kept isolated about $3 \cdot$ days before the bioassays. Then, naïve wasps were tested on substrates contaminated only with female $(\mathrm{F})$ or male $(\mathrm{M})$ traces following the general bioassay procedure described above. For each treatment 35 replicates were performed

\section{Experiment 2b. Effect of oviposition experience on egg parasitoid responses to chemical}

\section{footprints of the invasive stink bug species}

The aim of the experiment was to evaluate the influence of a successful rewarded experience (i.e. oviposition by $T$. basalis females on eggs of $H$. halys) on the subsequent wasps' behavioural responses to $H$. halys footprints. Naive $T$. basalis females were singly released onto a circular area contaminated with traces of host males or females and with a $H$. halys egg-mass (five to six eggs) in the middle. During this "training" phase, the residence time of the wasp was not recorded since we were interested in the response of experienced wasps. Then, experienced wasps (i.e. those that parasitized at least one egg) were recaptured and kept isolated in a small vial for $1 \mathrm{~h}$ or $24 \mathrm{~h}$. They were then tested on another arena treated with $H$. halys according to two treatment combinations: (1) oviposition in the presence of female traces and tested on female traces (F_Ov_F) or (2) oviposition in the presence of male traces and tested on male traces (M_Ov_M). For each treatment 24-31 successful replicates were performed

\section{Experiment 2c. Effects of unrewarded (footprints) and/or rewarded (oviposition)} experiences on egg parasitoid response to chemical footprints of the resident or invasive stink bug species 
In this experiment, we evaluated several possible combinations of rewarded and unrewarded experience to assess the subsequent wasps' behavioural responses to footprints in a scenario in which both stink bug species are present. Specifically, single T. basalis females were subjected to "training phases" by releasing the wasps onto a circular area to gain the following unrewarded and rewarded experiences: a) Contact on $N$. viridula female traces + oviposition experience on $N$. viridula eggs (Tr_Nv+Ov_Nv); b) Contact on $H$. halys female traces + oviposition experience on $N$. viridula eggs $\left(\mathrm{Tr} \_\mathrm{Hh}+\mathrm{Ov} \_\mathrm{Nv}\right)$; c) Contact on $N$. viridula female traces + oviposition experience on $H$. halys eggs $\left(\mathrm{Tr} \_\mathrm{Nv}+\mathrm{Ov} \_\mathrm{Hh}\right)$; d) Contact on $H$. halys female traces + oviposition experience on $H$. halys eggs (Tr_Hh+Ov_Hh); e) Oviposition experience on H. halys eggs (Ov_Hh); f) Oviposition experience on $N$. viridula eggs (Ov_Nv); g) Contact on $H$. halys female traces (Tr_Hh); h) Contact on $N$. viridula female traces (Tr_Nv); as controls naive wasps that had no experience on bug walking traces or oviposition were used. Treatments e) and f) represent unrealistic situations because the presence of stink bug eggs is always associated with walking traces, however we included these two training treatments to experimentally decuple the effects of the bug walking traces and the effects of oviposition. A successful oviposition experience was defined when the wasp marked the parasitized host by sweeping its ovipositor on the chorion surface. The acceptance rate displayed by T. basalis females was very high $(>90 \%$ MCF personal observations), regardless of the host being N. viridula or H. halys.

During the training phases, the total arena residence time of the wasps was not recorded. Then, the wasp was recaptured and tested after $1 \mathrm{~h}$ on filter paper arenas contaminated with female traces of the associated host $N$. viridula (so called "Nv-wasps") or the invasive stink bug H. halys (so called "Hh-wasps"). We chose $1 \mathrm{~h}$ time interval between training and testing bouts as the effects of experience was "forgotten" at $24 \mathrm{~h}$ (see results of experiment 2). The experience of contact on bugs female traces was defined after observing the typical wasp 
arrestment response on the contaminated area. For each treatment 28-30 successful replicates were performed

\section{Statistical analyses}

For experiment 1, we analysed differences in proportional data (eggs abortion, emergence of nymphs and parasitoids) between treatments ( $N$. viridula or H. halys) with Fisher's Exact Test. Differences in the size of emerged T. basalis females between treatments were analysed with a Linear Model (LM) with normal error distribution and identity link function.

Residence time data of experiment 2 were not normally distributed (which is typical of timeto-event data) and thus were analysed with General Linear Models (GLMs) fitting gamma error distribution and a reciprocal link function (Crawley 2007). For experiment 2a we used a GLM to test the effect of $H$. halys sex on the residence time of unexperienced wasps. For experiment $2 \mathrm{~b}$, we used a GLM with successful oviposition experience on $H$. halys eggs, time interval (1h and 24h) and the time interval $\times$ oviposition interaction as explanatory factors using parasitoid residence time as response variable. For experiment $2 \mathrm{c}$, we used a GLM with footprint experience, oviposition experience, stink bug species identity and their interactions as explanatory factors using parasitoid residence time as response variable. Due to a significant 3-way interaction, residence time data were analysed separately depending on whether experienced wasps were tested on $H$. halys footprints (i.e. Hh-wasps) or on $N$. viridula footprints (i.e. Nv-wasps).

Significance of the explanatory factors in GLMs was determined using Likelihood Ratio Tests (LRTs) comparing the full model with and without the factor in question (Crawley 2007). If models detected significant differences amongst factor levels, we proceeded to pairwise comparisons to determine which differed using the glht function in the multcomp 
260 from $F$-tests (Crawley 2007). Model fit was assessed with residual plots. All statistical

261 analyses were performed with R software version 3.1.3 (R Core Team 2013)

262 


\section{Experiment 1. Reproductive success of egg parasitoids developing in the invasive stink} bug species

Baseline levels of stink bug mortality in the absence of parasitism were low for both $H$. halys

Trissolcus basalis did develop in the eggs of the non-associated host $H$. halys but a development on the eggs of the associated host $N$. viridula $\left(\chi^{2}=64.71, \mathrm{df}=1, P<0.001\right)$; A significantly higher percentage $(81.34 \%)$ of host egg abortion was observed in H. halys compared with abortion levels in $N$. viridula $\left(\chi^{2}=68.21\right.$, df $\left.=1, P<0.001\right)$. Such high levels of $H$. halys egg abortion, which differ significantly with baseline levels observed in the absence of parasitism, are an indirect evidence of the high level of acceptance by T. basalis. Finally, no statistical differences were observed on the percentage of nymphs emerged between the associated and the non-associated host $\left(\chi^{2}<0.01, \mathrm{df}=1, P=0.986\right)$ (Fig 1A). The size of $T$. basalis females, as estimated by the hind tibia length, was strongly affected by the treatment $(F=46.81, \mathrm{df}=1,45 P<0.001)$. Wasps emerging from eggs of the invasive host $H$. halys were, on average, $23.15 \%$ larger than those emerging from $N$. viridula host eggs (Fig 1B).

\section{Experiment 2a. Egg parasitoid innate responses to chemical footprints of the invasive}

Naïve T. basalis females responded to chemical footprints of the non-associated stink bug halys male chemical footprints $\left(\chi^{2}=0.65, \mathrm{df}=1, P=0.398\right)$ (Fig. 2). 

Experiment 2b. Effect of successful oviposition experience on egg parasitoid responses to chemical footprints of the invasive stink bug species

The residence time of $T$. basalis wasps was significantly affected by successful oviposition experience $\left(\chi^{2}=1.98, \mathrm{df}=1, P=0.075\right)$ and the time interval $\left(\chi^{2}=2.65, \mathrm{df}=1, P=0.0012\right)$ between experience events. Wasps previously rewarded with an oviposition experience on $H$. halys eggs that re-encountered $H$. halys female footprints after 1 h showed longer arena residence time compared to rewarded wasps re-encountering $H$. halys male chemical footprints (Fig. 3). Parasitoids showed no discrimination between areas contaminated by chemical footprints left by a host female or host male when the time interval between training and testing bouts was $24 \mathrm{~h}$ (Fig. 3).

\section{Experiment 2c. Effects of unrewarded (footprints) and/or rewarded (oviposition)} stink bug species

Residence time on H. halys female traces. The response of $T$. basalis wasps to substrates contaminated with footprints of the non-associated host $H$. halys was affected by oviposition experience $\left(\chi^{2}=12.01, \mathrm{df}=2, P<0.001\right)$, by experience on footprints $\left(\chi^{2}=7.67, \mathrm{df}=2, P\right.$ $<0.001)$ and by the oviposition $\times$ footprint interaction $\left(\chi^{2}=37.98, \mathrm{df}=4, P<0.001\right)$ (Fig. 4A). Wasps that previously oviposited on the non-associated host in the presence of footprints (i.e. Tr_Nv +Ov_Hh and Tr_Hh+Ov_Hh) achieved high values of residence time similar to naïve wasps, regardless if footprint experience occurred on the native or invasive host (Fig. 4A). 
$+\mathrm{Ov} \_\mathrm{Nv}$ and Tr_Hh+Ov_Nv) lower levels of residence time were found, and again the footprint experience did not affect wasp response (Fig. 4A). The residence time of wasps previously exposed to $N$. viridula oviposition only (Ov_Nv) was not different than residence time of wasps rewarded with oviposition experience on $H$. halys only (Ov_Hh) (Fig. 4A).

315 Finally, wasps spent the lowest residence time when given an unrewarded experience (i.e. no 316 oviposition), especially when trained on the footprints of the non-associated hosts (Tr_Hh) 317 (Fig. 4A).

318 Residence time on $N$. viridula female traces. The response of $T$. basalis wasps to substrates contaminated with footprints of the associated host $N$. viridula was affected by the previous oviposition experience $\left(\chi^{2}=7.98, \mathrm{df}=2, P<0.001\right)$ and by the oviposition $\times$ footprint interaction $\left(\chi^{2}=4.08, \mathrm{df}=4, P=0.015\right)$ whereas no effect of the footprint experience itself was found $\left(\chi^{2}=0.72\right.$, df $\left.=2, P=0.396\right)$ (Fig. 4B). Wasps rewarded with oviposition experience on the associated host $N$. viridula (i.e. Tr_Nv+Ov_Nv, Tr_Hh+Ov_Nv, Ov_Nv) showed high levels of responses in terms of residence time, similar to those of naïve wasps (Fig. 4B). An oviposition experience on the invasive species $H$. halys induced overall lower residence times by $T$. basalis, although significant differences were only observed between $H$. halys oviposition only (Ov_Hh) and all $N$. viridula treatments in which oviposition occurred, regardless of the presence or identity of the footprint experience (Fig. 4B). Unrewarded experience decreased the wasp residence times on host footprints, especially when wasps were trained on the footprints of the associated host $N$. viridula $\left(\mathrm{Tr} \_\mathrm{Nv}\right)$ (Fig. 4B). 


\section{Discussion}

334 In this paper we investigated the ecological consequence of exotic herbivore invasion for the fitness of a non-associated egg parasitoid species. We showed that $H$. halys can act as an evolutionary trap for the egg parasitoid $T$. basalis and that foraging experience by the wasp on cues associated with the invasive stink bug species does not lead to the avoidance of an evolutionary trap.

Our results showed that the egg parasitoid $T$. basalis accepts $H$. halys eggs as ovipositional sites, yet $\sim 95 \%$ of the parasitoid eggs failed to develop indicating that $H$. halys represents a clear, poor reproductive investment. In the recent years there has been an increase in the number of studies that documented evolutionary traps in insects (see Robertson et al. 2013 for a review). In egg parasitoids, the taxonomically related $T$. podisi also experienced the invasive $H$. halys as an egg sink although the severity of the trap may be higher for this egg parasitoid species because T. podisi parasitoids always failed to successfully develop (Abram et al. 2014). Interestingly, the few T. basalis parasitoids that emerged from $H$. halys eggs are almost $25 \%$ larger in size, as estimated by the hind tibia length, probably because the wasps benefit from the greater amount of resources contained in H. halys eggs compared with the smaller $N$. viridula host eggs (Martorana et al. 2017). Because body size is a good proxy for fitness (Boivin et al. 2010; Cusumano et al. 2016; Roitberg et al. 2001) it is possible that wasps emerging from $H$. halys eggs may have a competitive advantage compared with those developing on the associated host $N$. viridula.

353 This hypothesis suggests potentially "mixed consequences" of attacking an unsuitable host/evolutionary trap as the value of producing larger offspring could partially offset the negative consequences of producing fewer offspring. Such trade-off could be particularly important for species like T. basalis that fight over reproductive investments (Field and

357 Calbert 1998). 

the walking traces of the invasive stink bug species, suggesting a chemical similarity between contact kairomones of $H$. halys and $N$. viridula, the preferred host of T. basalis. However, the similarly between chemical cues of the associated versus non-associated host is only partial, because naive $T$. basalis wasps cannot discriminate between the footprints left by male and female adult bugs of $H$. halys. In closely associated egg parasitoid-stink bug systems (i.e. $T$. basalis - N. viridula; Trissolcus brochymenae - Murgantia histrionica; Trissolcus sp. chemical residues, with stronger intensity of responses induced by footprints of female bugs, especially if in preovipositional state (Colazza et al. 1999; Peri et al. 2013, 2016; Salerno el al. 2009).

Interestingly, the plasticity of wasp responses depends on experience, as wasps rewarded with an oviposition in $H$. halys eggs learn to discriminate between traces left by females compared with traces left by males. If $H$. halys would be a suitable host for $T$. basalis, this type of experience-induced behavioural response would likely be adaptive as female host traces are a more reliable indicator of the presence of host eggs. However, because the link between cue reliability and resource suitability is broken in evolutionary traps (Schapfer et al. 2005), this response to H. halys cues does not maximize the reproductive success of $T$. basalis. The host gender discrimination is time-dependent and it is only displayed when the time interval between wasp training and testing bouts is of $1 \mathrm{~h}$, suggesting that the learned information is stored in short term memory (Hoedjes et al. 2011; Margulies et al. 2005).

We also assessed the effect of unrewarded and rewarded experiences on the patch time allocation of the egg parasitoid in "mixed" conditions, i.e. when cues of both H. halys and $N$. 
climate models predict that the invasive stink bug species will continue to spread in North America and Europe (Kriticos et al. 2017; Zhu et al. 2012) thus increasing the degree of overlap with the geographic regions where $N$. viridula and $T$. basalis are already present. Furthermore, $N$. viridula and $H$. halys share many plant hosts so direct overlap is likely to be inevitable. In such mixed scenarios we found that: 1) wasps tested on $H$. halys female traces (i.e. Hh-wasps) achieved high intensity of responses when they experienced a successful oviposition on $H$. halys eggs regardless of the nature of the footprints; 2) wasps tested on $N$. viridula female traces (i.e. Nv-wasps) achieved high intensity of responses when wasps previously oviposited on $N$. viridula regardless of the nature/presence of the footprints. Taken together, these results indicate that $T$. basalis females display the strongest responses when they obtained an oviposition experience on the same stink bug species used for the subsequent tests. A possible explanation for our results is that the oviposition experience overrules the effect of the footprint experience being the former stimulus of higher hierarchical value for the fitness of the wasp (Vinson et al. 1998). Our results challenge the wasps.

An interesting difference between the behavioural responses of Nv-wasp and Hh-wasp is found when wasp females receive an unrewarded experience (i.e. footprints only) on the naïve wasps) than Nv-wasp response on $N$. viridula (50.75\% reduction compared with naïve wasps). This appears to be adaptive because, under unrewarded conditions, T. basalis could became quickly habituated and lose motivation to respond to $H$. halys kairomones. 
"trapped" by its behavioural responses to the invasive stink bug species, as long as it is not rewarded by an oviposition experience before habituation takes place.

An invasive exotic species can indirectly affect the interactions between an indigenous parasitoid and its hosts (Heimpel et al. 2003; Desurmont et al. 2014; Kenis et al 2009). Several lines of evidence suggest that the presence of an invasive species such as $H$. halys may interfere with the efficiency of $T$. basalis as biological control agent of $N$. viridula given the fact that: 1) the parasitoid spends time investigating chemical cues associated with the low-suitable resource, time that could be spent foraging for the associated host; 2) the parasitoid wastes $\sim 95 \%$ of eggs when oviposition in $H$. halys occurred, eggs that could be invested into associated hosts which yield higher fitness payoffs; 3) the parasitoid appears to value an oviposition reward on $N$. viridula eggs at a similar level (or even lower) than an oviposition in $H$. halys eggs. It would be thus interesting to monitor parasitism rates of $T$. basalis on $N$. viridula in those areas in which H. halys has recently established to evaluate if $N$. viridula has become a more destructive pest and whether this is due to insufficient biological control.

It is remarkable to note that our population of $T$. basalis, which originated from individuals collected in Sicily, develops on viable $H$. halys eggs although with a very low success rate, whereas another Italian population (Umbria region) of the wasp cannot do so (Rondoni et al. 2017); such findings suggest that this egg parasitoid species has the potential to "escape" the evolutionary trap. In fact, a recent study conducted in North America showed that another population of $T$. basalis can develop on $H$. halys eggs with relatively high reproductive success (38\% of the parasitoids emerged as adults) (Balusu et al. 2019). This means that ovipositing in a $H$. halys egg mass does not constitute a dead end for the parasitoid and, if there will be selective pressure and underlying genetic variation in developmental success for natural selection to act on, it is possible that over evolutionary 
time $T$. basalis could form a more stable association with the invasive stink bug species. Yet,

434 the impact of $H$. halys for T. basalis is difficult to predict and will depend on several

435 ecological aspects including the frequency of encounter with $H$. halys egg masses and the

436 preference of the indigenous parasitoid for eggs of the invasive species over the associated

437 host.

438 When invasive species are introduced in novel environments, or expand their range

439 towards the poles due to global warming, they interact with native organisms in several direct

440 and indirect ways (Kenis et al. 2009; Vilá et al. 2011). Due to the lack of co-evolutionary

441 history, invasive species can create novel ecological scenarios in which the behavioural

442 responses of indigenous organisms do not maximize fitness (Robertson et al. 2013; Schaper

443 et al. 2005). Here we show that an invasive stink bug species which acts as an evolutionary

444 trap affects the behavioural responses of experienced indigenous egg parasitoids. Our study

445 shows that experience is not necessarily helpful for native species responding to an

446 evolutionary trap because, at least in the short term, it seems to reinforce the maladaptive

447 behaviour (Bertoldi 2020). Future studies should focus on whether, in the long term, this

448 reinforcement could actually make adaptation to the host more likely. This is a topic of

449 particular relevance nowadays in both basic and applied ecology given the increasing

450 frequency of invasion of exotic species in non-native environments.

451

452 


\section{References}

Aartsma Y, Cusumano A, Fernández de Bobadilla M, Rusman Q, Vosteen I, Poelman EH (2019) Understanding insect foraging in complex habitats by comparing trophic levels: insights from specialist host-parasitoid-hyperparasitoid systems. Curr Opin Insect Sci $32: 54-60$

Abram PK, Cusumano A, Abram K, Colazza S, Peri E (2017) Testing the habituation assumption underlying models of parasitoid foraging behavior. PeerJ 5:e3097

Abram PK, Gariepy TD, Boivin G, Brodeur J (2014) An invasive stink bug as an evolutionary trap for an indigenous egg parasitoid. Biol Invasions 6:1387-95

Bertoldi V (2020) Effect of an invasive alien pentatomid pest on local multi-trophic systems. $\mathrm{PhD}$ Thesis, University of Perugia.

Balusu RR, Talamas EJ, Cottrell TE, Toews MD, Blaauw BR, Sial AA, Buntin DG, Fadamiro HY, Tillman G (2019) First record of Trissolcus basalis (Hymenoptera: Scelionidae) parasitizing Halyomorpha halys (Hemiptera: Pentatomidae) in the United States. Biodivers Data J 7: e39247

Berkvens N, Moens J, Berkvens D, Samih MA, Tirry L, De Clercq P (2010) Dinocampus coccinellae as a parasitoid of the invasive ladybird Harmonia axyridis in Europe. Biol Control 53: 92-99

Boivin G (2010) Phenotypic plasticity and fitness in egg parasitoids. Neotrop Entomol 39:457-463

Bretz F, Hothorn T, Westfall PH (2010) Multiple comparisons using R (Chapman and Hall/CRC)

Carlsson N.O, Sarnelle O, Strayer DL (2009) Native predators and exotic prey-an acquired taste? Front Ecol Environ 7: 525-532 
477 Colazza S, Cusumano A, Giudice DL, Peri E (2014) Chemo-orientation responses in

478

479

480

481

482

483

484

485

486

487

488

489

490

491

492

493

494

495

496

497

498

499

500 hymenopteran parasitoids induced by substrate-borne semiochemicals. BioControl 59:1-17

Colazza S, Salerno G, Wajnberg E (1999) Volatile and contact chemicals released by Nezara viridula (Heteroptera: Pentatomidae) have a kairomonal effect on the egg parasitoid Trissolcus basalis (Hymenoptera: Scelionidae). Biol Control 16:310-317

Corrêa-Ferreira BS, Moscardi F (1996) Biological control of soybean stink bugs by inoculative releases of Trissolcus basalis. Entomol exp appl 79: 1-7

Crawley MJ (2007) The R book (John Wiley \& Sons, Wiley Ltd, Chichester England)

Cusumano A, Peri E, Colazza S (2016) Interspecific competition/facilitation among insect parasitoids. Curr Opin Insect Sci 6: 14-12

Cusumano A, Peri E, Vinson SB, Colazza S (2011) Intraguild interactions between two egg parasitoids exploring host patches. BioControl, 56:173-184

Desurmont GA, Harvey J, van Dam NM, Cristescu SM, Schiestl FP, Cozzolino S, Anderson P, Larsson MC, Kindlmann P, Danner H, Turlings TC (2014). Alien interference: disruption of infochemical networks by invasive insect herbivores. Plant Cell Environ 37:1854-1865

Fatouros NE, Dicke M, Mumm R, Meiners T, Hilker M (2008) Foraging behavior of egg parasitoids exploiting chemical information. Behav Ecol 19:677-689

Field S, Calbert G (1998) Patch defence in the parasitoid wasp Trissolcus basalis: when to begin fighting? Behaviour, 135: 629-642.

Foti MC, Peri E, Wajnberg E, Colazza S, Rostás M (2019) Contrasting olfactory responses of two egg parasitoids to buckwheat floral scent are reflected in field parasitism rates. $\mathbf{J}$ Pest Sci 92:747-56. 
Gandhi KJ, Herms DA. (2010) Direct and indirect effects of alien insect herbivores on ecological processes and interactions inforests of eastern North America. Biol Invasions 12: $389-405$

Haye T, Fischer S, Zhang J, Gariepy T (2015) Can native egg parasitoids adopt the invasive brown marmorated stink bug, Halyomorpha halys (Heteroptera: Pentatomidae), in Europe? J Pest Sci 88: 693-705

Heimpel GE, Neuhauser C, Hoogendoorn M (2003) Effects of parasitoid fecundity and host resistance on indirect interactions among hosts sharing a parasitoid. Ecol Lett 6:556566

Hoedjes KM, Kruidhof HM, Huigens ME, Dicke M, Vet LEM, Smid HM (2011) Natural variation in learning rate and memory dynamics in parasitoid wasps: opportunities for converging ecology and neuroscience. Proc R Soc B 278:889-897

Hoogendoorn M, Heimpel GE (2002) Indirect interactions between an introduced and a native ladybird beetle species mediated by a shared parasitoid. Biol Control 25:224230

Holt RD (1977) Predation, apparent competition, and the structure of prey communities. Theor Popul Biol 12:197-229

Jones WA (1988) World review of the parasitoids of the southern green stink bug, Nezara viridula (L.)(Heteroptera: Pentatomidae). Ann Entomol Soc Am 81:262-273

Kenis M, Auger-Rozenberg M, Roques A, Timms L, Péré C, Cock MJ, Settele J, Augustin S, Lopez-Vaamonde C (2009) Ecological effects of invasive alien insects. Biol Invasions 11: $21-45$

Konopka JK, Poinapen D, Gariepy T, Holdsworth DW, McNeil JN (2020) Timing of failed parasitoid development in Halyomorpha halys eggs. Biol Control 141:104-124 
Konopka JK, Poinapen D, Gariepy T, McNeil JN (2018) Understanding the mismatch between behaviour and development in a novel host-parasitoid association. Sci Rep 8: $1-11$

Kriticos DJ, Kean JM, Phillips CB, Senait D, Senay HA, Haye T (2017) The potential global distribution of the brown marmorated stink bug, Halyomorpha halys, a critical threat to plant biosecurity. J Pest Sci 90, 1033-1043

Leskey TC, Nielsen AL (2018). Impact of the invasive brown marmorated stink bug in North America and Europe: history, biology, ecology, and management. Annu Rev Entomol 63:599-618

Margulies C, Tully T, Dubnau J (2005) Deconstructing memory in Drosophila. Curr Biol $15: 700-713$

Martorana, L Foti MC, Rondoni G, Conti E, Colazza S, Peri E (2017) An invasive insect herbivore disrupts plant volatile-mediated tritrophic signalling. J Pest Sci 90:1079_ 1095

Meiners T, Peri E (2013) Chemical ecology of insect parasitoids: essential elements for developing effective biological control programmes. In: Wajnberg E, Colazza S (eds) Chemical ecology of insect parasitoids. Wiley-Blackwell, UK, pp 193-224

Peri E, Frati F, Salerno G, Conti E, Colazza S (2013) Host chemical footprints induce host sex discrimination ability in egg parasitoids. PloS one 8:e79054

Peri E, Salerno G, Slimani T, Frati F, Conti E, Colazza S, Cusumano A (2016). The response of an egg parasitoid to substrate-borne semiochemicals is affected by previous experience. Sci Rep 6:27098

Peri E, Sole MA, Wajnberg E, Colazza S (2006). Effect of host kairomones and oviposition experience on the arrestment behavior of an egg parasitoid. J Exp Biol 209: 3629-3635 
R Core Team (2013) R: A language and) environment for statistical computing. Vienna (Austria). R Foundation for statistical computing

Redman AM, Scriber JM (2000) Competition between the gypsy moth, Lymantria dispar, and the northern tiger swallowtail, Papilio canadensis: interactions mediated by host plant chemistry, pathogens, and parasitoids. Oecologia 125: 218-228

Rice KB, Bergh CJ, Bergmann EJ, Biddinger DJ, Dieckhoff C Dively G et al. (2014) Biology, Ecology, and Management of Brown Marmorated Stink Bug (Hemiptera: Pentatomidae). J Integr Pest Manag 5: 1-13

Robertson BA, Blumstein DT (2019) How to disarm an evolutionary trap. Conservation Science and Practice. 1:e116.

Robertson BA, Rehage JS, Sih A (2013) Ecological novelty and the emergence of evolutionary traps. Trends Ecol Evol 28:552-60

Roitberg BD, Boivin G, Vet LEM (2001) Fitness, parasitoids, and biological control: an opinion. Can Entomol 133: 429-438

Rondoni G, Bertoldi V, Malek R, Foti MC, Peri E, Maistrello L, Haye T, Conti E (2017) Native egg parasitoids recorded from the invasive Halyomorpha halys successfully exploit volatiles emitted by the plant-herbivore complex. J Pest Sci 90:1087-1095

Roversi FP, Binazzi F, Marianelli L, Costi E, Maistrello L, Peverieri GS 2016. Searching for native egg-parasitoids of the invasive alien species Halyomorpha halys Stål (Heteroptera Pentatomidae) in Southern Europe. Redia 99: 63-70

Salerno G (2000) Evaluation of host specificity in pentatomid parasitoids through their response to the host unit. $\mathrm{PhD}$ Thesis, University of Perugia.

Salerno G Frati F, Conti E, De Pasquale C, Peri E, Colazza S (2009) A finely tuned strategy adopted by an egg parasitoid to exploit chemical traces from host adults. J Exp Biol 212: $1825-1831$ 
Schlaepfer MA, Runge MC, Sherman PW (2002) Ecological and evolutionary traps. Trends Ecol Evol 17:474-480

Schlaepfer MA, Sherman PW, Blossey B, Runge MC (2005) Introduced species as evolutionary traps. Ecol Lett 8:241-246

Settle W, Wilson L (1990) Invasion by the variegated leafhopper and biotic interactions: parasitism, competition, and apparent competition. Ecology 71: 1461-1470

Sloggett JJ (2010) Predation of ladybird beetles by the orb-web spider Araneus diadematus. BioControl 55: 631-638

Smid HM, Vet LEM (2016) The complexity of learning, memory and neural processes in an evolutionary ecological context. Curr Opin Insect Sci15:61-9.

Talamas EJ, Buffington ML, Hoelmer K (2017) Revision of Palearctic Trissolcus Ashmead (Hymenoptera, Scelionidae). In: Talamas EJ, Buffington ML (Eds) Advances in the Systematics of Platygastroidea. Hymenopt Res 56: 3-185

Todd JW (1989) Ecology and behavior of Nezara viridula. Ann Rev Entomol 34:273-292

Vilá M, Espinar JL, Hejda M, Hulme PE, Jarošík V, Maron JL Pyšek P (2011) Ecological impacts of invasive alien plants: a meta-analysis of their effects on species, communities and ecosystems. Ecol Lett 14: 702-708

Vinson SB (1998) The general host selection behavior of parasitoid Hymenoptera and a comparison of initial strategies utilized by larvaphagous and oophagous species. Biol Control 11:79-96.

Zhu G, Bu W, Gao Y, Liu G (2012) Potential geographic distribution of brown marmorated stink bug invasion (Halyomorpha halys). PLoS One 7:e31246 


\section{Legends}

Fig. 1. (A) Development of parasitoids in invasive and resident hosts. Proportion of emerged parasitoids, dead host eggs and emerged stink bug nymphs observed when Trissolcus basalis females were exposed to stink bug eggs of the invasive species Halyomorpha halys (Hh, white colour) and the resident host Nezara viridula (Nv, grey colour) and. Proportion of dead host eggs and emerged stink bug nymphs in unexposed control eggs are shown to display the baseline levels of host mortality and egg viability in both N. viridula and H. halys. Asterisks indicate significantly different proportions within each developmental outcome $\left(\chi^{2}\right.$ tests, $\left.\mathrm{P}<0.05\right)$. Solid lines refer to pairwise comparisons between stink bug species whereas dashed lines indicate within species comparisons. (B) Size of egg parasitoids emerging from invasive and resident hosts. Hind tibia length of Trissolcus basalis developed on stink bug eggs of Halyomorpha halys (Hh, white colour) and Nezara viridula (Nv, grey colour). Asterisks indicate significant differences (LM, $\mathrm{P}<0.05)$.

Fig. 2. Behavioural response of naïve parasitoids to chemical traces of the invasive host. Mean (+ SE) residence time of Trissolcus basalis females encountering for the first time (naïve), Halyomorpha halys walking traces left onto a filter paper arena by female (F) or male bugs (M). "ns" above bars indicates no significantly different means (GLM, P < 0.05).

Fig. 3. Behavioural response of parasitoids with rewarded experience to chemical traces of the invasive host. Mean (+ SE) residence time of Trissolcus basalis females allowed to oviposit on Halyomorpha halys eggs in the presence of either host female or male traces and then tested after $1 \mathrm{~h}$ or $24 \mathrm{~h}$ according to different conditions: $\mathrm{F}_{-} \mathrm{O}$ __F $=$ oviposition in the presence of female traces and tested on female traces; $\mathrm{M} \_\mathrm{O}$ __M $=$ oviposition in the presence 
621 of male traces and tested on male traces. Asterisks above bars indicate significantly different means $(\mathrm{GLM}, \mathrm{P}<0.05)$

623

624 Fig. 4. Behavioural responses of experienced parasitoids to chemical traces left by

625 Halyomorpha halys females (4A) or by Nezara viridula females (4B). Mean (+ SE)

626 residence time of Trissolcus basalis females experienced according to different conditions,

627 rewarded or non rewarded, on the invasive host Halyomorpha halys (white bars) or on the

628 resident host Nezara viridula (grey bars). Naïve $=$ no experience on host walking traces or

629 oviposition; $\mathrm{Tr} \_\mathrm{Nv}+\mathrm{Ov} \_\mathrm{Nv}=$ Contact on $N$. viridula female traces + successful oviposition experience on $N$. viridula eggs; Tr_Hh+Ov_Nv = Contact on $H$. halys female traces + successful oviposition experience on $N$. viridula eggs; Tr_Nv +Ov_Hh $=$ Contact on $N$. viridula female traces + successful oviposition experience on $H$. halys eggs; $\mathrm{Tr} \_\mathrm{Hh}+\mathrm{Ov} \_\mathrm{Hh}$ = Contact on $H$. halys female traces + successful oviposition experience on $H$. halys eggs; Ov_Hh = successful oviposition experience on $H$. halys eggs; Ov_Nv = successful oviposition experience on $N$. viridula eggs; $\mathrm{Tr} \_\mathrm{Hh}=$ contact on $H$. halys female traces; Tr_Nv $=$ contact on $N$. viridula female traces. Different letters above bars indicate significantly different means (GLM, P < 0.05) 
A)

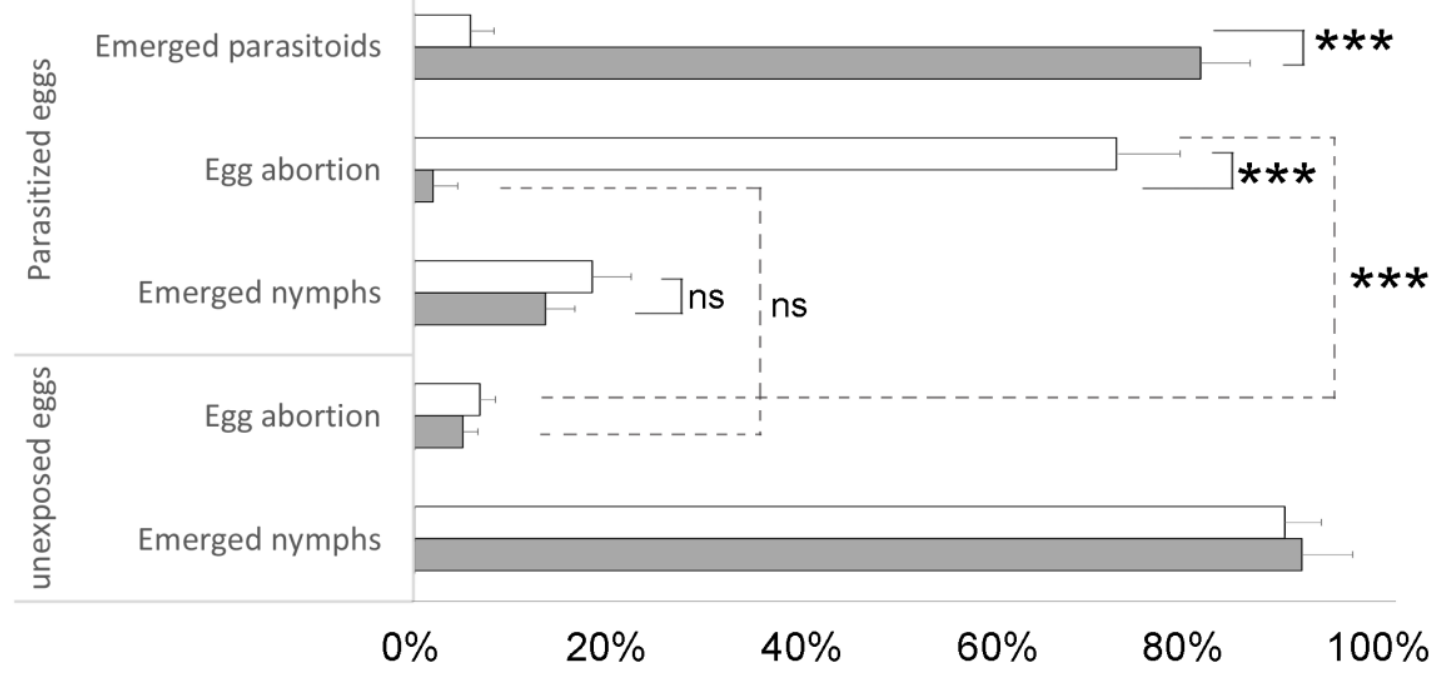

$\square$ Hh

$\square \mathrm{Nv}$

B)

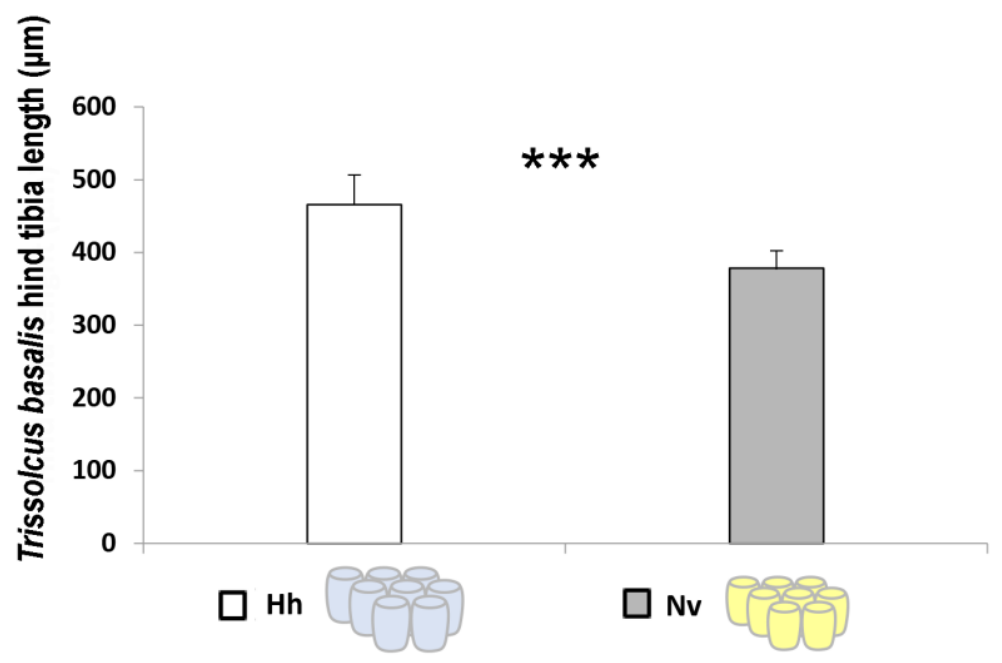

640

641 
642 Fig. 2

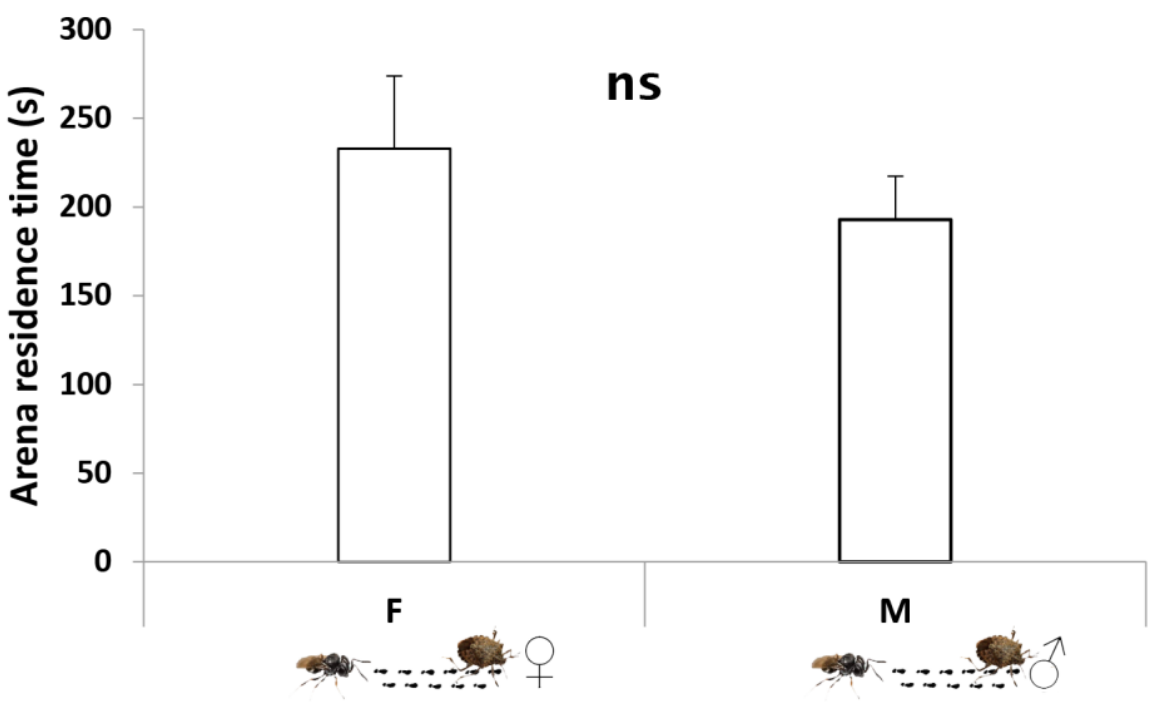

643

644 
645 Fig. 3

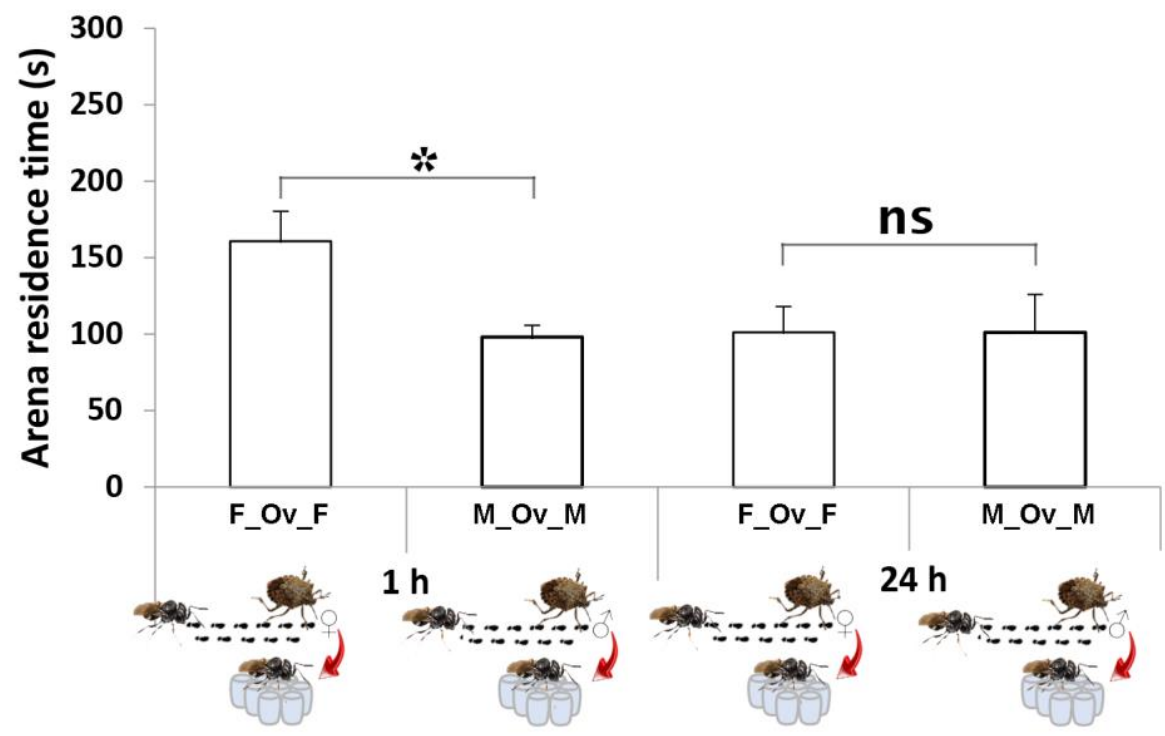

646

647 
Fig. 4

A)

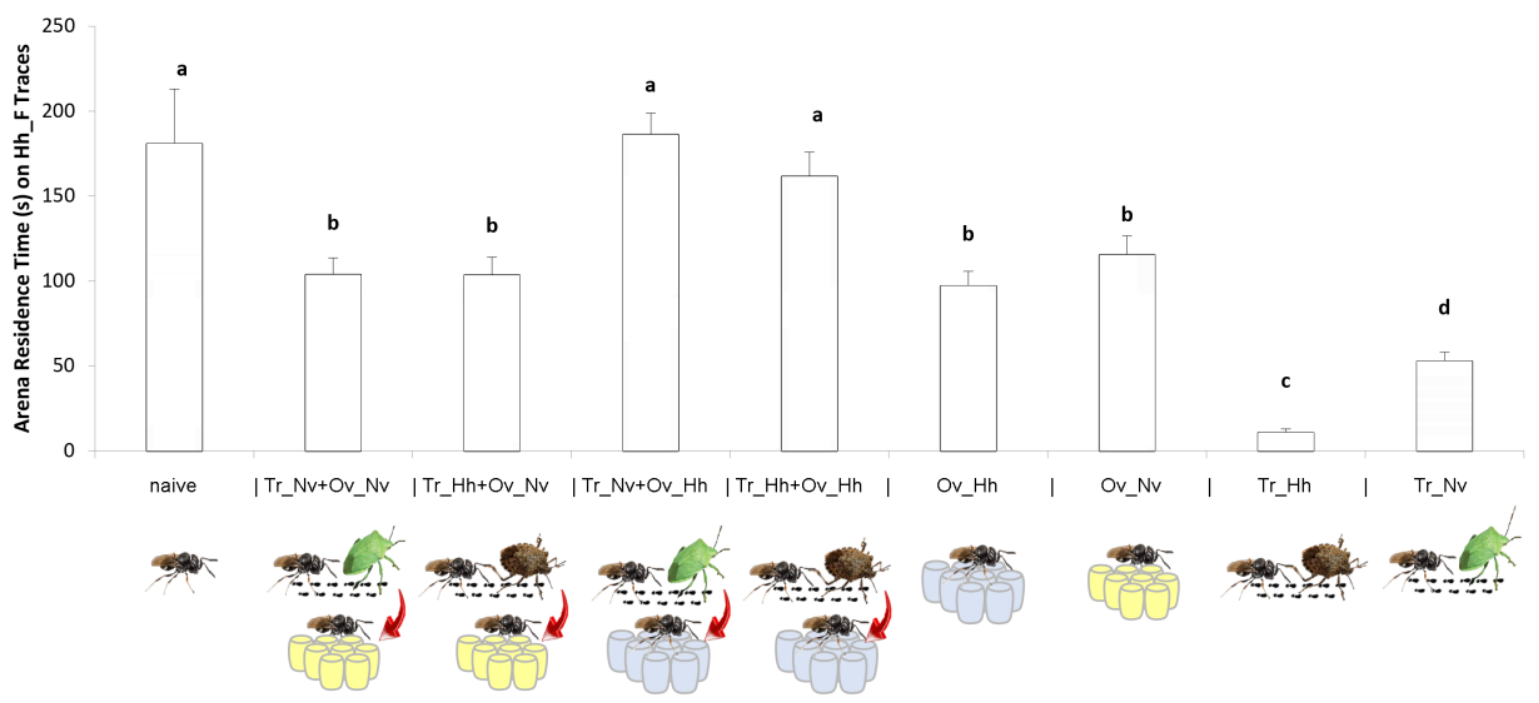

B)

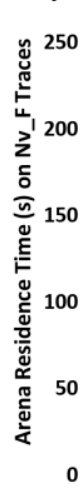

649
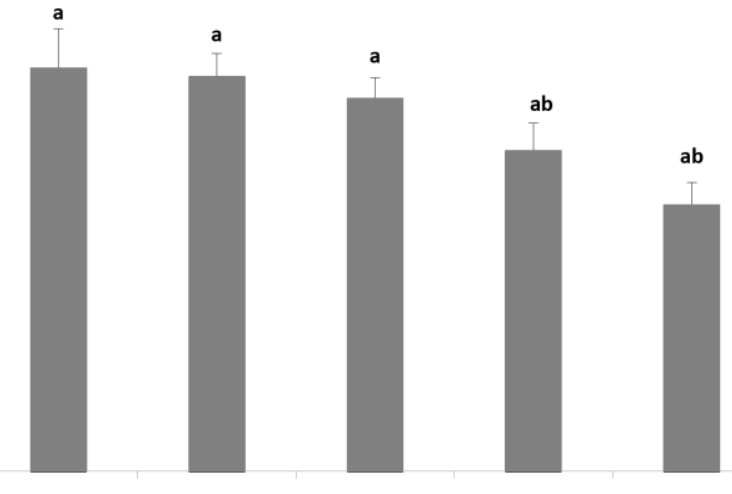

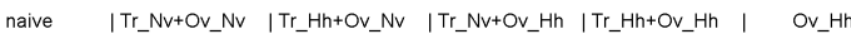

Ov_Nv | Tr_Hh | Tr_Nv

प्रer-
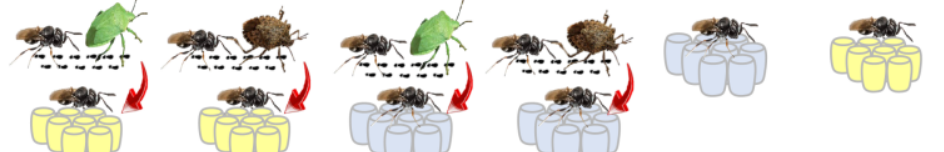

\% 


\section{Acknowledgements}

This research was supported by the Marie Skłodowska-Curie Research and Innovation Staff Exchange (RISE) H2020-MSCA-RISE-2015 of the European Union with the project Impact of invasive alien true bug species in native trophic webs - INVASIoN (GA 690952). We thank Milko Sinacori for technical assistance and Paul Abram (Agriculture and Agri-Food Canada) for helpful comments on an earlier draft of the manuscript. 


\section{Compliance with Ethical Standards}

There are no ethical concerns regarding the organisms and the topic of this research 